\title{
InfluênCia do Período de RestriçÃo Hídrica na AtIVIdade RESIDUAL DE ISOXAFLUTOLE NO SOLO ${ }^{1}$
}

\author{
Influence of Drought Periods on the Residual Activity of Isoxaflutole in Soil
}

\author{
OLIVEIRA JR., R.S. ${ }^{2}$, MARCHIORI JR., O. ${ }^{3}$, CONSTANTIN, J. ${ }^{2}$ e INOUE, M.H. ${ }^{4}$
}

\begin{abstract}
RESUMO - O objetivo deste trabalho foi estudar a atividade residual do isoxaflutole (IFT) no controle de Brachiaria decumbens sob diferentes períodos de seca, após a aplicação do herbicida, em dois solos. Para isso, foram realizados seis ensaios simultâneos, sendo utilizadas doses de 0, 230 e $270 \mathrm{~g} \mathrm{ha}^{-1}$ de isoxaflutole em amostras de Latossolo Vermelho Distroférrico nitossólico (textura argilosa) e doses de 0, 180 e $200 \mathrm{~g} \mathrm{ha}^{-1}$ em amostras de Latossolo Vermelho distrófico (textura franco-argilo-arenosa). Em cada ensaio, foram combinados em esquema fatorial doses e períodos de seca após as aplicações do herbicida, utilizando-se B. decumbens como bioindicador da atividade residual do herbicida no solo. As avaliações de controle foram feitas aos 15, 30, 45 e 60 dias após a semeadura do bioindicador. O IFT apresentou alta estabilidade no solo de textura argilosa mesmo após três chuvas simuladas de $20 \mathrm{~mm}$, espaçadas de 30 dias e seguidas de 120 dias de seca após sua aplicação. No solo de textura franco-arenosa a estabilidade foi menor, e o efeito residual (80\% de controle) persistiu entre 0 e 110 dias para $B$. decumbens, conforme dose, períodos de seca e data de avaliação após a semeadura. Esse fato evidenciou que, à medida que aumenta o tempo e o número de irrigações entre a aplicação do herbicida e a semeadura do bioindicador, há redução no potencial efetivo de controle de IFT no Latossolo Vermelho distrófico.
\end{abstract}

Palavras-chave: bioindicador, herbicidas, resíduos.

\begin{abstract}
This work was carried out to evaluate the residual activity of isoxaflutole (IFT) in Brachiaria decumbens control after different simulated drought conditions following herbicide application in two soils. Six simultaneous experiments were performed, using rates of 0,230 and $270 \mathrm{~g} \mathrm{ha}^{-1}$ of IFT in samples of a heavy clay soil and of 0,180 and $200 \mathrm{~g} \mathrm{ha}^{-1}$ in samples of a sandy clay loam soil. In each experiment, rates of IFT were combined in a factorial scheme with drought periods after herbicide application. B. decumbens was used as bioindicator of the residual activity of IFT in soil. Visual control of bioindicator was evaluated at 15, 30, 45 and 60 days after sowing. IFT was very stable when applied to the heavy clay soil, even after three $20 \mathrm{~mm}$ simulated rain, 30 days apart from each other, and followed by 120 days of drought conditions. Stability was shorter for the sandy clay loam soil and residual activity (t $80 \%$ control) ranged from 0 to 110 days for $\boldsymbol{B}$. decumbens, depending on rate, drought periods and evaluation date. Results indicate that as period of time and number of irrigation events between herbicide application and bioindicator sowing increased, residual control of IFT decreased on the sandy clay loam soil.
\end{abstract}

Keywords: bioindicator, herbicides, residues.

Recebido para publicação em 6.2.2006 e na forma revisada em 10.11.2006.

Parte da dissertação do primeiro autor apresentada para obtenção do título de Mestre em Agronomia, área de concentração de Proteção de Plantas.

2 Professor Adjunto, Departamento de Agronomia - UEM, <rsojunior@uem.br>, Bolsista do CNPq; ${ }^{3}$ Eng.-Agr., M.S., Universidade Estadual de Maringá - UEM; ${ }^{4}$ Eng.-Agr., D.S. - UEM, Professora do curso de Agronomia da Faculdade Integrado de Campo Mourão.

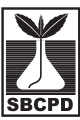

Planta Daninha, Viçosa-MG, v. 24, n. 4, p. 733-740, 2006 


\section{INTRODUÇÃO}

Muitos processos envolvidos na dinâmica dos herbicidas no ambiente ainda são desconhecidos. No entanto, o entendimento das interações entre solo, planta e herbicida é determinante na recomendação adequada a cada tipo de solo, com maior eficiência e menor contaminação do ambiente. Particularmente, para solos brasileiros, com grande variabilidade das características físicas, químicas e biológicas, espera-se que a eficiência, o efeito residual, a lixiviação e a sorção dos herbicidas sejam também diferentes.

Para o isoxaflutole (IFT), a sua sorção no solo diminui com o decréscimo do teor de matéria orgânica e com o aumento do $\mathrm{pH}$ do solo. Por sua vez, o conteúdo de argila e a concentração de $\mathrm{Ca}^{2+}$ não afetam o grau de sorção de IFT. Conforme Mitra et al. (1999), em solos com teores de matéria orgânica maiores ou iguais a $2 \%$, a sorção, a persistência e a mobilidade do IFT no solo correlacionam-se com o teor de matéria orgânica, mas não com a textura. Além disso, o IFT não persiste em concentrações altas no solo, devido, principalmente, à sua hidrólise. Segundo Taylor-Lovell et al. (2002), sua meia-vida diminui de 74 para 38 horas quando a umidade do solo passa de 10 para 40\%; se o solo estiver seco, essa reação não ocorre ou se dá muito lentamente.

No solo, o IFT é rapidamente convertido em metabólito diquetonitrila (DKN), que é a molécula biologicamente ativa no controle de plantas daninhas. O DKN é mais solúvel (326 $\mathrm{mg} \mathrm{L}^{-1}$ ), mais estável e mais persistente que o IFT (Taylor-Lovell et al., 2000, 2002; Mitra et al., 2000). Posteriormente, o DKN é convertido em ácido benzóico $(\mathrm{AB})$, que é considerado um metabólito biologicamente inativo, embora muito estável. Uma vez que a solubilidade do DKN em água é cerca de 50 vezes maior do que a do IFT, espera-se maior disponibilidade de DKN na solução do solo com menor sorção (Taylor-Lovell et al., 2000), a qual também diminui com o decréscimo de matéria orgânica presente no solo (Mitra et al., 2000).

Atualmente, o IFT é recomendado para o controle de plantas daninhas em milho, mandioca, batata, algodão e cana-de-açúcar (Rodrigues \& Almeida, 2005). Nessas culturas, esse herbicida pode ser usado em pré e pósemergência precoce (Vidal \& Merotto Jr., 2001). Seus sintomas característicos são bleaching de tecidos desenvolvidos após a aplicação nas espécies suscetiveis, seguindo-se paralisação do crescimento e necrose (Pallet et al., 1998). Os sintomas foliares estão associados com o acúmulo do fitoeno, típico dos herbicidas que inibem o fitoeno desaturase. No entanto, o DKN inibe a 4-hydroxyphenylpyruvate dioxygenase (HPPD), com inibição indireta do fitoeno desaturase resultante da depleção de um co-fator essencial, a plastoquinona (Pallet et al., 1998; Viviani et al., 1998).

Considerando que em condições de seca, após a aplicação de IFT, podem ocorrer alterações nas doses utilizadas desse herbicida, o objetivo deste trabalho foi avaliar a influência da umidade de dois solos distintos na atividade residual de isoxaflutole.

\section{MATERIAL E MÉTODOS}

Foram instalados seis experimentos em casa de vegetação. As amostras de solos utilizadas nos ensaios foram provenientes do horizonte subsuperficial (5 a $20 \mathrm{~cm}$ ) de dois locais: Centro Tecnológico de Irrigação (Latossolo Vermelho distroférrico nitossólico) e Fazenda Experimental de Iguatemi (Latossolo Vermelho distrófico). As características físicas e químicas das amostras dos solos encontram-se na Tabela 1.

Após a coleta, as amostras foram preparadas como TFSA; posteriormente, foram acondicionadas em vasos plásticos com percolação e capacidade de 5 litros, sendo cada vaso considerado uma unidade experimental.

As aplicações de IFT foram realizadas no solo seco, em pré-emergência, utilizando-se pulverizador costal de pressão constante à base de $\mathrm{CO}_{2}$, com bicos tipo leque XR-110-02 e pressão de $2,0 \mathrm{kgf} \mathrm{cm}^{-2}$, o que proporcionou um volume de 150 litros de calda por hectare.

Em cada experimento, foram combinados em esquema fatorial períodos de seca e doses do herbicida, em delineamento inteiramente casualizado, com três repetições. As doses foram diferentes para cada tipo de solo. Para cada experimento, os períodos de seca se iniciaram após a aplicação do herbicida, nas 
Tabela 1 - Características químicas e físicas de amostras dos solos utilizadas nos experimentos

\begin{tabular}{|c|c|c|c|c|c|c|c|c|c|c|c|c|}
\hline \multirow{2}{*}{ Solo } & \multicolumn{2}{|c|}{$\mathrm{PH}$} & $\mathrm{Al}^{3+}$ & $\mathrm{H}^{+}+\mathrm{Al}^{3+}$ & $\mathrm{Ca}^{+2}+\mathrm{Mg}^{2+}$ & $\mathrm{Ca}^{2+}$ & $\mathrm{K}^{+}$ & $\mathrm{P}$ & $\mathrm{C}$ & Areia & Silte & Argila \\
\cline { 2 - 14 } & $\left(\mathrm{CaCl}_{2}\right)$ & $\left(\mathrm{H}_{2} \mathrm{O}\right)$ & \multicolumn{6}{|c|}{$\left(\mathrm{cmol}_{\mathrm{c}} \mathrm{dm}^{-3}\right)$} & & \multicolumn{3}{|c|}{$(\%)$} \\
\hline $\mathrm{LV}^{1 /}$ & 4,1 & 6,0 & 0,2 & 3,68 & 9,97 & 6,75 & 0,24 & 1 & 10,36 & 12 & 16 & 72 \\
\hline $\mathrm{LR}^{2 /}$ & 4,0 & 4,9 & 0,7 & 3,42 & 1,64 & 1,03 & 0,07 & 1 & 3,07 & 65 & 8 & 27 \\
\hline
\end{tabular}

${ }^{1 /} \mathrm{LV}=$ Latossolo Vermelho distroférrico nitossólico (textura argilosa).

${ }^{2} / \mathrm{LR}=$ Latossolo Vermelho distrófico (textura franco-argilo-arenosa).

respectivas doses para cada solo, e também após a aplicação de uma ou mais lâminas de água $(20 \mathrm{~mm})$, de acordo com cada experimento. Sempre que houve mais de uma aplicação de lâminas de água, observou-se um intervalo de 30 dias entre as lâminas.

Dessa forma, nos experimentos 1 e 2 foram aplicadas três doses do IFT para cada tipo de solo. As doses de isoxaflutole foram de 0, 230 e $270 \mathrm{~g} \mathrm{ha}^{-1}$ para as amostras de Latossolo Vermelho distroférrico nitossólico (textura argilosa) e de 0, 180 e $200 \mathrm{~g} \mathrm{ha}^{-1}$ para as amostras de Latossolo Vermelho distrófico (textura franco-argilo-arenosa). Após a pulverização do herbicida, aplicou-se uma lâmina de água de $20 \mathrm{~mm}$, seguida pelos períodos de seca que se iniciaram a partir da aplicação da lâmina de água e foram de 30, 60, 90 e 120 dias após a aplicação (DAA). Ao final de cada período de seca, semeou-se Brachiaria decumbens, avaliando-se o efeito residual de herbicida.

Nos experimentos 3 e 4, foram aplicadas as mesmas doses de IFT em cada solo. Depois da pulverização, aplicaram-se 20 mm de água, esperou-se um intervalo de 30 dias e aplicouse mais $20 \mathrm{~mm}$ de água. Imediatamente após a segunda lâmina de água, iniciaram-se os períodos de seca de 0, 30, 60 e 90 dias. Ao final de cada um desses períodos semeou-se $B$. decumbens para verificar o efeito residual do herbicida nessas condições.

Nos experimentos 5 e 6, novamente foram aplicadas as mesmas doses de IFT para cada solo. Entretanto, foram aplicados $60 \mathrm{~mm}$ de lâmina de $20 \mathrm{~mm}$ de água, divididos em três irrigações de $20 \mathrm{~mm}$ a cada 30 dias após a aplicação do herbicida. Os períodos de seca iniciaram-se imediatamente após a terceira lâmina de chuva e foram de 0, 30, 60, 90 e 120 dias, com a semeadura de $B$. decumbens ao final de cada período.

Em todos os experimentos, a partir da semeadura da espécie bioindicadora, os vasos foram mantidos com irrigação até o encerramento das avaliações de controle, as quais foram realizadas aos 15, 30, 45 e 60 dias após a semeadura (DAS) de B. decumbens, por meio de escala visual (0-100\%), sendo 0\% nenhum controle e $100 \%$ morte total das plantas, utilizando-se a testemunha sem aplicação do herbicida como referência (SBCPD, 1995).

Os dados de controle do bioindicador foram analisados por meio de análise de variância e ajuste das regressões das curvas segundo as médias estudadas, utilizando-se o pacote estatístico SAEG (1997).

\section{RESULTADOS E DISCUSSÃO}

\section{Experimentos 1 e 2}

A análise de variância pelo teste $F(D=5 \%)$ evidenciou que para o Latossolo Vermelho distroférrico nitossólico apenas o fator dose foi significativo, ao passo que para o Latossolo Vermelho distrófico tanto os fatores isolados quanto a interação entre ambos foram significativos. Dessa forma, as curvas de regressão para doses e períodos foram ajustadas apenas para o solo Latossolo Vermelho distrófico (Tabela 2). Já para o Latossolo Vermelho distroférrico nitossólico verificou-se que, independentemente da dose (230 e $270 \mathrm{~g} \mathrm{ha}^{-1}$ ) e do período de seca após a aplicação e a primeira simulação de chuva, o controle foi muito estável. Assim, optou-se por não ajustar a equação de regressão para o Latossolo Vermelho 
Tabela 2 - Equações da regressão obtidas para porcentagem de controle de $B$. decumbens para cada combinação de dose de isoxaflutole e DAS no Latossolo Vermelho distrófico (experimento 2)

\begin{tabular}{|c|c|c|c|c|}
\hline Dose $\left(\mathrm{g} \mathrm{ha}^{-1}\right)$ & DAS & $\mathrm{R}^{2}$ & $\mathrm{Y}=\mathrm{a}+\mathrm{bP}+\mathrm{cP}^{2}$ & Duração de $\mathrm{P}$ para $\mathrm{Y}=80$ \\
\hline 180 & 15 & 0,87 & $128,417-(0,960556 \mathrm{P})+\left(0,00175927 \mathrm{P}^{2}\right)$ & 56 \\
\hline 200 & 15 & 0,77 & $121,50-(0,725556 \mathrm{P})+\left(0,00166667 \mathrm{P}^{2}\right)$ & 67 \\
180 & 30 & 0,78 & $126,00-(0,751111 \mathrm{P})+\left(0,000370373 \mathrm{P}^{2}\right)$ & 63 \\
200 & 30 & 0,68 & $116,75-(0,567222 \mathrm{P})+\left(0,00212963 \mathrm{P}^{2}\right)$ & 50 \\
180 & 45 & 0,91 & $142,50-(1,42111 \mathrm{P})+\left(0,00648148 \mathrm{P}^{2}\right)$ & 70 \\
200 & 45 & 0,87 & $144,167-(1,43778 \mathrm{P})+\left(0,00481483 \mathrm{P}^{2}\right)$ & 54 \\
180 & 60 & 0,89 & $123,167-(0,662222 \mathrm{P})+\left(0,000740749 \mathrm{P}^{2}\right)$ & 50 \\
200 & 60 & 0,76 & $125,667-(0,608888 \mathrm{P})-\left(0,000296295 \mathrm{P}^{2}\right)$ & 58 \\
\hline
\end{tabular}

Em todas as equações, $\mathrm{Y}=$ controle visual $(\%)$ e $\mathrm{P}=$ período de seca após a aplicação (dias). DAS = dias após a semeadura.

distroférrico nitossólico, uma vez que o controle observado foi sempre igual ou superior a $97 \%$, como constatado por Marchiori Jr. et al. (2005).

Com base nas equações de regressão, observou-se que aos 15 DAS, para a dose de $180 \mathrm{~g} \mathrm{ha}^{-1}$ de IFT (Figura la e Tabela 2), o controle só foi eficaz (acima de $80 \%$ ) até o período de 56 dias de seca. O aumento da dose para $200 \mathrm{~g} \mathrm{ha}^{-1}$ de IFT (Figura 1b e Tabela 2) prolongou o controle efetivo até 67 dias com restrição hídrica. Isso indica que, conforme avança o período em dias em que o solo permaneceu seco, o controle sobre BRADC é prejudicado.

Na dose de $180 \mathrm{~g} \mathrm{ha}^{-1}$ de IFT, aos 60 DAS (Figura 1c e Tabela 2) há efeito satisfatório de controle de BRADC - 80\% até o período de 70 dias de seca. Já para a dose de $200 \mathrm{~g} \mathrm{ha}^{-1}$ de IFT (Figura 1d e Tabela 2) verificaram-se controles acima de $80 \%$ sobre BRADC até o período de 58 dias e, a partir daí, uma redução drástica no controle. Os dados indicam que após a aplicação de IFT em Latossolo Vermelho distrófico, seguida de irrigação de $20 \mathrm{~mm}$ e após seca prolongada, mesmo assim seria possível controlar o fluxo de BRADC pelo mínimo de 56 dias.

\section{Experimentos 3 e 4}

A análise de variância dos dados provenientes tanto do Latossolo Vermelho distroférrico nitossólico (experimento 3) quanto do Latossolo Vermelho distrófico (experimento 4) mostra o mesmo comportamento em relação às fontes de variação que apresentaram efeito significativo quando comparado aos experimentos 1 e 2. Em ambas as doses aplicadas (230 e $270 \mathrm{~g} \mathrm{ha}^{-1}$ ) no Latossolo Vermelho distroférrico nitossólico verificou-se excelente controle de BRADC (acima de 97\%), mesmo quando esta foi semeada 120 dias após a aplicação do herbicida e passado por esse período de restrição hídrica. Não havendo efeito significativo da interação, não foi necessário ajustar as equações de regressão. Esses dados reiteram o potencial do IFT/DKN em permanecer no solo Latossolo Vermelho distroférrico nitossólico por um período prolongado, uma vez que, somando-se o período após a aplicação do IFT, têm-se 30 dias (condição inicial), mais até 120 dias (períodos em que as sementes de BRADC foram semeadas nos vasos após o final da condição inicial) e mais 60 dias (período das avaliações após a semeadura de BRADC nos vasos), o que totaliza 210 dias com controle praticamente total do bioindicador.

A sorção do IFT, assim como do DKN, é influenciada primariamente pela matéria orgânica do solo, ao passo que o teor de argila tem menor influência (Mitra et al., 1999), a qual cresce em solos com baixos teores de matéria orgânica (Mitra et al., 2000). No entanto, no campo, os componentes minerais e a matéria orgânica estão intimamente associados, de modo que os efeitos individuais são difíceis de separar (Mitra et al., 2000).

O Latossolo Vermelho distroférrico nitossólico, além de apresentar teor elevado de argila em relação ao Latossolo Vermelho distrófico $(72 \% \times 27 \%)$, ainda apresenta três vezes 
mais carbono orgânico $\left(10,36\right.$ x 3,07 $\mathrm{g} \mathrm{dm}^{-3}$, Tabela 1), o que pode explicar a maior retenção no solo Latossolo Vermelho distroférrico nitossólico e, por conseqüência, a maior atividade residual.

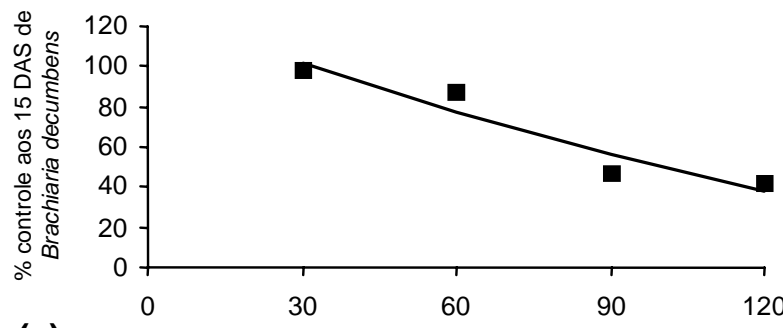

(a) Período de seca após a aplicação e a última chuva (dias)

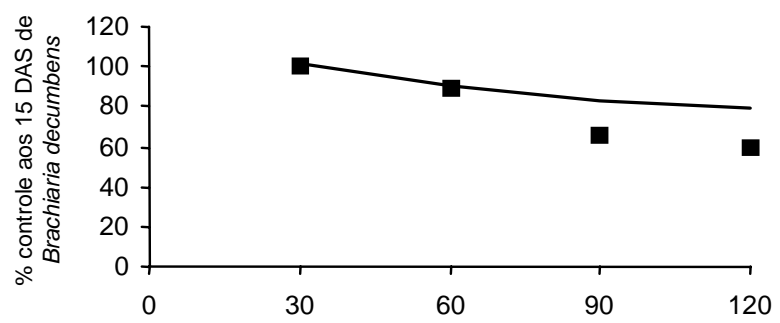

(b) Período de seca após a aplicação e a última chuva (dias)
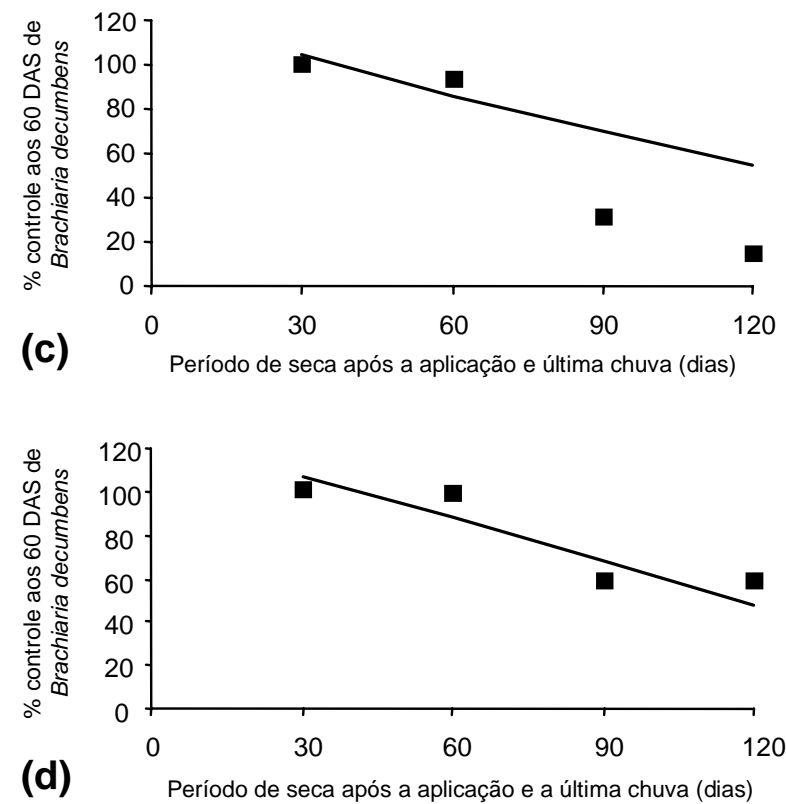

Figura 1 - Controle de BRADC ( dados observados, - dados estimados) aos 15 (A) e 60 (C) DAS, na dose de $180 \mathrm{~g} \mathrm{ha}^{-1}$, e aos 15 (B) e 60 (D) DAS, na dose de $200 \mathrm{~g} \mathrm{ha}^{-1}$ DAS, aplicado em solo Latossolo Vermelho distrófico (Experimento 2-20 $\mathrm{mm}$ de lâmina de água).
Para o solo Latossolo Vermelho distrófico, a interação dose e período foi desdobrada por equações de regressão de períodos dentro de cada dose (Tabela 3). De modo geral, o efeito residual de ambas as doses aplicadas no solo Latossolo Vermelho distrófico é menor do que aquele observado para as doses aplicadas no solo Latossolo Vermelho distroférrico nitossólico. Embora as doses sejam diferentes para cada tipo de solo (180 e $200 \mathrm{~g} \mathrm{ha}^{-1}$ para o Latossolo Vermelho distrófico e 230 e $270 \mathrm{~g} \mathrm{ha}^{-1}$ para o Latossolo Vermelho distroférrico nitossólico), elas foram baseadas na recomendação de uso do fabricante. Esse fato ocorre, aparentemente, em função da maior sorção pelo Latossolo Vermelho distroférrico nitossólico, o qual necessitaria de doses mais elevadas para promover controle satisfatório. Os dados indicam a possibilidade de que, mesmo sob condições adversas de umidade de solo (condição inicial), é possível reduzir as doses de IFT e, mesmo assim, obter controle satisfatório das espécies suscetíveis. Vale lembrar que o bioindicador utilizado nestes experimentos é considerado uma das gramíneas menos suscetiveis ao IFT e que, neste trabalho, consideram-se como aceitáveis niveis de controle iguais ou superiores a $80 \%$.

No Latossolo Vermelho distrófico, a dose de $180 \mathrm{~g} \mathrm{ha}^{-1}$ permitiu controle efetivo de BRADC no máximo com 10 dias de seca após a condição inicial, considerando-se a última avaliação (60 DAS) (Figura 2c e Tabela 3). Para a dose de $200 \mathrm{~g} \mathrm{ha}^{-1}$, controles satisfatórios foram obtidos por até 53 dias de seca após o final da condição inicial, considerando-se apenas a avaliação final (60 DAS de BRADC) (Figura 2d e Tabela 3). Neste solo, o nível de controle foi reduzido consistentemente à medida que se aumentou o período de tempo entre o final da condição inicial e a semeadura de BRADC (Figura 2), que implica maiores períodos de seca.

\section{Experimentos 5 e 6}

Para o Latossolo Vermelho distroférrico nitossólico, apenas os efeitos isolados de dose e período foram significativos, ao passo que a interação entre ambos foi não-significativa. Já para o Latossolo Vermelho distrófico, tanto os fatores isolados quanto a interação foram significativos. 
Sob as condições iniciais, a dose de $180 \mathrm{~g} \mathrm{ha}^{-1}$ não foi considerada efetiva em nenhuma das avaliações (15, 30, 45 e 60 DAS) dos diferentes períodos de seca, proporcionando sempre menos que $80 \%$ de controle de BRADC. Na Figura 3a e c são apresentadas as tendências de controle inicial (15 DAS) e final (60 DAS), respectivamente, de BRADC. A elevação da dose para $200 \mathrm{~g} \mathrm{ha}^{-1}$ permitiu atingir controle aceitável de BRADC por periodos variando entre 7 e 40 dias de seca após o final da condição inicial, exceto para as avaliações realizadas aos 15 DAS (Tabela 4). Neste caso, o controle de BRADC já parte de um patamar inferior a $80 \%$ (Figura 3b), enquanto nas avaliações realizadas aos 60 DAS o controle foi efetivo para condições de até 14 dias de seca após a condição inicial (Figura 3d e Tabela 4).

Ao comparar os experimentos 2 e 4 , observa-se que o aumento de um período de
30 dias de seca e de uma irrigação de 20 mm reduziu o potencial efetivo de controle do IFT no Latossolo Vermelho distrófico. Tomandose como referência apenas as avaliações aos 60 DAS, as doses de 180 e $200 \mathrm{~g} \mathrm{ha}^{-1}$ proporcionariam controles aceitáveis de fluxos de BRADC que emergissem por 70 e 58 dias de seca após a condição inicial do experimento 2 , ao passo que, sob as condições do experimento 4, tais controles seriam de 10 e 53 dias de seca após a condição inicial deste experimento. Comparando-se ainda esses dados com aqueles do experimento 6, é possivel concluir que a adição de um novo período de seca de 30 dias mais nova irrigação de $20 \mathrm{~mm}$ proporcionariam controles aceitáveis por 0 (zero) e 14 dias de seca após a condição inicial deste experimento, respectivamente. É conveniente ressaltar, no entanto, que as condições simuladas nos experimentos 5 e 6 são extremas, uma vez que simulam uma precipitação

Tabela 3 - Equações da regressão obtidas para porcentagem de controle de B. decumbens, em cada combinação de dose de isoxaflutole e DAS, no Latossolo Vermelho distrófico (experimento 4)

\begin{tabular}{|c|c|c|c|c|}
\hline Dose $\left(\mathrm{g} \mathrm{ha}^{-1}\right)$ & DAS & $\mathrm{R}^{2}$ & $\mathrm{Y}=\mathrm{a}+\mathrm{bP}+\mathrm{cP}^{2}$ & Duração de $\mathrm{P}$ para $\mathrm{Y}=80$ \\
\hline 180 & 15 & 0,67 & $80-(1,0111 \mathrm{P})+\left(0,0055555 \mathrm{P}^{2}\right)$ & 0 \\
\hline 200 & 15 & 0,78 & $90,67-(0,55841 \mathrm{P})+\left(0,00322751 \mathrm{P}^{2}\right)$ & 22 \\
\hline 180 & 30 & 0,66 & $86,30-(0,62476 \mathrm{P})+\left(0,0017989 \mathrm{P}^{2}\right)$ & 10 \\
\hline 200 & 30 & 0,79 & $95,40-(0,168413 \mathrm{P})+\left(0,000449736 \mathrm{P}^{2}\right)$ & 10 \\
\hline 180 & 45 & 0,75 & $90,73-(1,22667 \mathrm{P})+\left(0,00592592 \mathrm{P}^{2}\right)$ & 90 \\
\hline 200 & 45 & 0,69 & $97,26-(0,078888 \mathrm{P})-\left(0,0012963 \mathrm{P}^{2}\right)$ & 10 \\
\hline 180 & 60 & 0,77 & $93,56-(1,4596 \mathrm{P})+\left(0,0070899 \mathrm{P}^{2}\right)$ & 53 \\
\hline 200 & 60 & 0,78 & $99,30-(0,39365 \mathrm{P})+\left(0,000687828 \mathrm{P}^{2}\right)$ & 50 \\
\hline
\end{tabular}

Em todas as equações, $\mathrm{Y}=$ controle visual $(\%)$ e $\mathrm{P}=$ período de seca após a aplicação (dias). DAS = dias após a semeadura.

Tabela 4 - Equações da regressão obtidas para porcentagem de controle de $B$. decumbens, em cada combinação de dose de isoxaflutole e DAS, no Latossolo Vermelho distrófico (experimento 6)

\begin{tabular}{|c|c|c|c|c|}
\hline Dose $\left(\mathrm{g} \mathrm{ha}^{-1}\right)$ & DAS & $\mathrm{R}^{2}$ & $\mathrm{Y}=\mathrm{a}+\mathrm{bP}+\mathrm{cP}^{2}$ & Duração de $\mathrm{P}$ para $\mathrm{Y}=80$ \\
\hline 180 & 15 & 0,73 & $50,52-(0,796031 \mathrm{P})+\left(0,00436507 \mathrm{P}^{2}\right)$ & 0 \\
\hline 200 & 15 & 0,86 & $69,47-(0,607301 \mathrm{P})+\left(0,00285714 \mathrm{P}^{2}\right)$ & 0 \\
\hline 180 & 30 & 0,87 & $67,38-(0,76984 \mathrm{P})+\left(0,0031746 \mathrm{P}^{2}\right)$ & 40 \\
\hline 200 & 30 & 0,72 & $87,17-(0,0592067 \mathrm{P})-\left(0,00320106 \mathrm{P}^{2}\right)$ & 0 \\
\hline 180 & 45 & 0,69 & $45,33-(0,572222 \mathrm{P})+\left(0,0027777 \mathrm{P}^{2}\right)$ & 7 \\
\hline 200 & 45 & 0,77 & $84,68-(0,657936 \mathrm{P})+\left(0,0029365 \mathrm{P}^{2}\right)$ & 0 \\
\hline 180 & 60 & 0,78 & $63,99-(1,10047 \mathrm{P})+\left(0,00584655 \mathrm{P}^{2}\right)$ & 14 \\
\hline 200 & 60 & 0,67 & $92,37-(0,96365 \mathrm{P})+\left(0,00457671 \mathrm{P}^{2}\right)$ & 0 \\
\hline
\end{tabular}

Em todas as equações, $\mathrm{Y}=$ controle visual $(\%)$ e $\mathrm{P}=$ período de seca após a aplicação (dias). DAS = dias após a semeadura. 
total de $60 \mathrm{~mm}$ num período de apenas 60 dias, o que, mesmo para as condições de inverno do centro-sul do Brasil, é pouco provável.

Ao se compararem os experimentos 2, 4 e 6 , é possivel constatar ainda que a "piora" da condição inicial (aumento do período de tempo
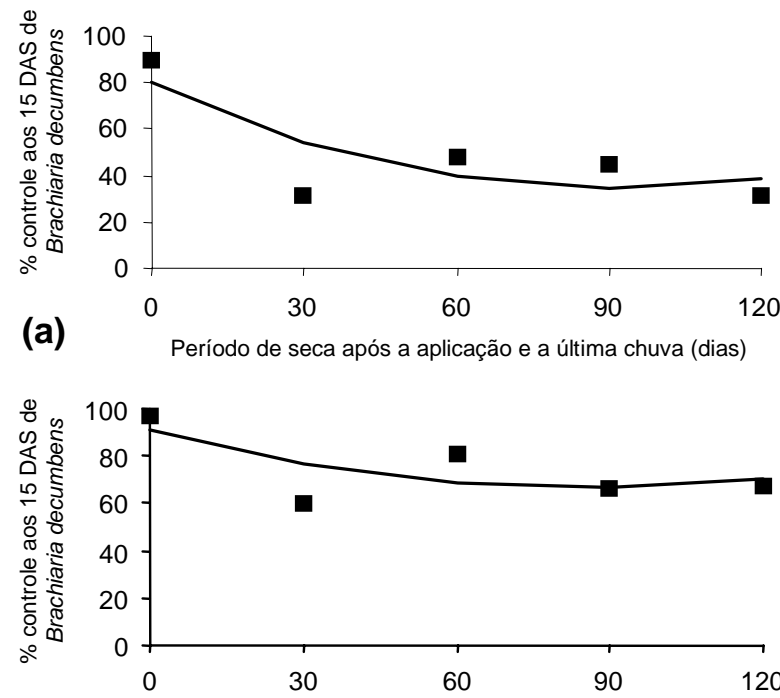

(b) Período de seca após a aplicação e a última chuva (dias)
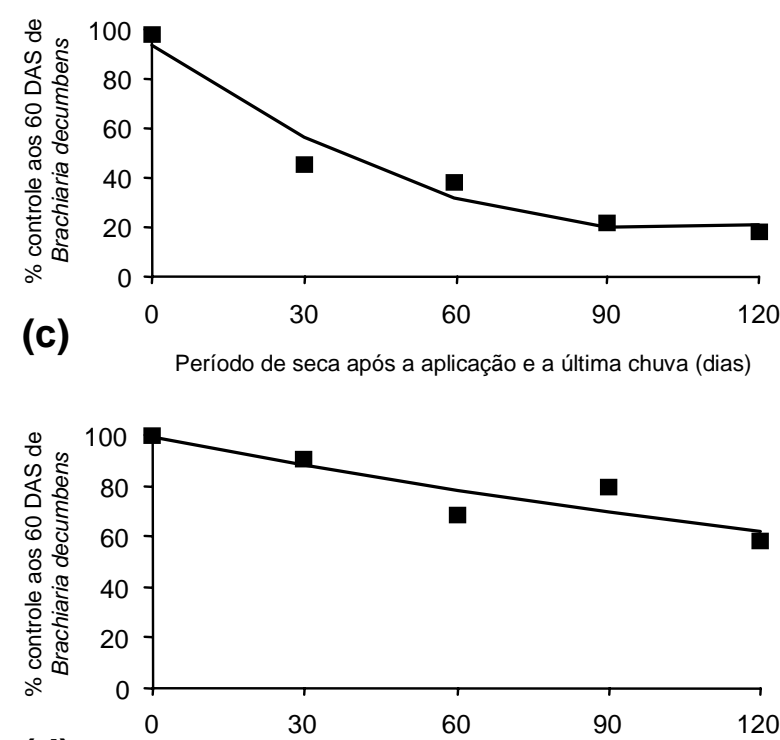

(d) Período de seca após a aplicação e a última chuva (dias)

Figura 2 - Controle de BRADC ( $\square$ dados observados, - dados estimados) aos 15 (A) e 60 (C) DAS, na dose de $180 \mathrm{~g} \mathrm{ha}^{-1}$, e aos 15 (B) e 60 (D) DAS, na dose de $200 \mathrm{~g} \mathrm{ha}^{-1}$ DAS, aplicado em solo Latossolo Vermelho distrófico (Experimento 4: 20 + $20 \mathrm{~mm}$ de lâmina de água). e do número de irrigações entre a aplicação do IFT e a semeadura da BRADC) afeta mais o controle inicial (15 DAS) do que o final (60 DAS), significando que, à medida que o tempo passa e os vasos recebem irrigação, ocorre um efeito de "recarga" na solução do solo, possivelmente do DKN.

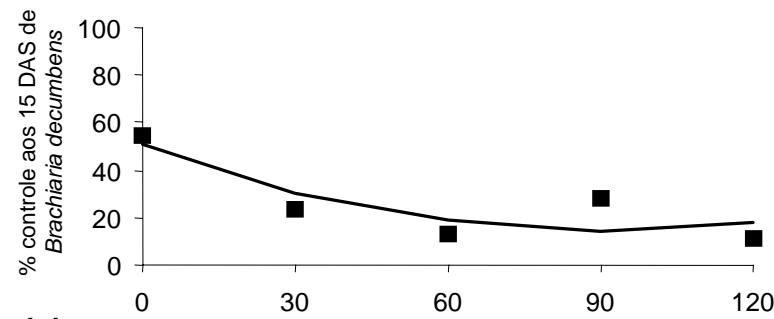

(a) Período de seca após a aplicação e a última chuva (dias)

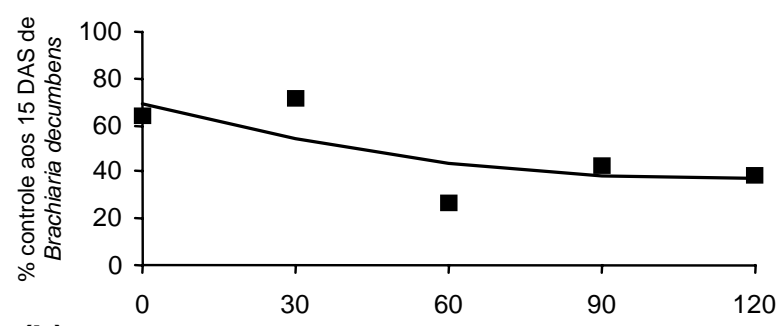

(b) Período de seca após a aplicação e a última chuva (dias)
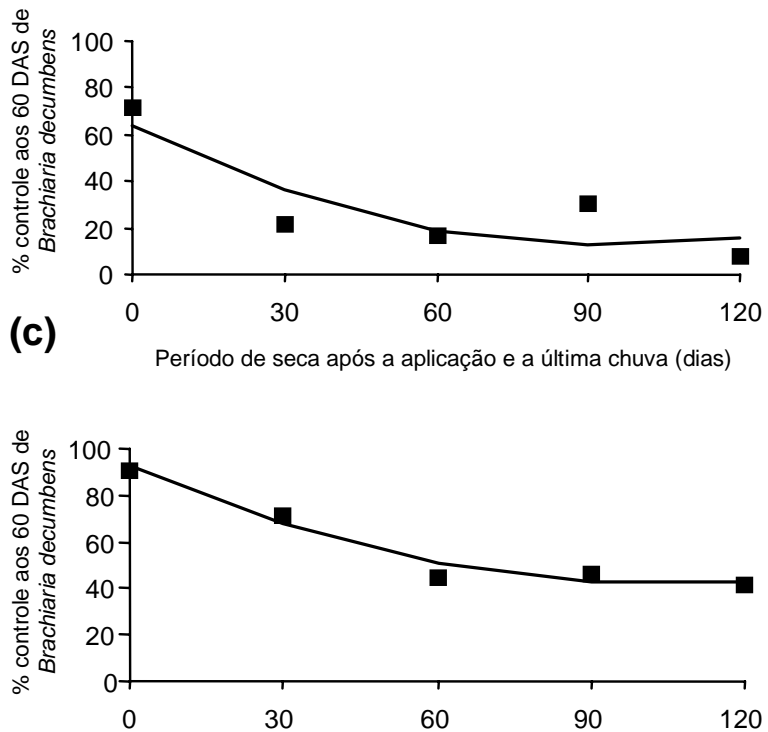

(d)

Período de seca após a aplicação e a última chuva (dias)

Figura 3 - Controle de BRADC ( $\square$ dados observados, - dados estimados) aos 15 (A) e 60 (C) DAS, na dose de $180 \mathrm{~g} \mathrm{ha}^{-1}$ e aos 15 (B) e 60 (D) DAS, na dose de $200 \mathrm{~g} \mathrm{ha}^{-1}$ DAS, aplicado em solo Latossolo Vermelho distrófico (Experimento 6: $20+20+20 \mathrm{~mm}$ de lâmina de água).

Planta Daninha, Viçosa-MG, v. 24, n. 4, p. 733-740, 2006 


\section{LITERATURA CITADA}

MARCHIORI JR., O. et al. Efeito residual de isoxaflutole após diferentes períodos de seca. Planta Daninha, v. 23, p. 491-499, 2005.

MITRA, S.; BHOWMILK, P. C.; XING, B. Sorption and desorption of the diketonitrile metabolite of isoxaflutole in soils. Environ. Poll., v. 108, p. 183-190, 2000.

MITRA, S.; BHOWMILK, P. C.; XING, B. Sorption of isoxaflutole by five different soils varying in physical and chemical properties. Pestic. Sci., v. 55, p. 935-942, 1999.

PALLET, K. E. et al. The mode of action of isoxaflutole. I. Physiological effects, metabolism, and selectivity. Pestic. Biochem. Physiol., v. 62, p. 113-124, 1998.

RODRIGUES, B. N.; ALMEIDA, F.S. Guia de herbicidas. 5.ed. Londrina: 2005. $592 \mathrm{p}$.

SAEG. Sistema para Análises Estatísticas, versão 7.0. Viçosa, MG: Fundação Arthur Bernardes, 1997.
SOCIEDADE BRASILEIRA DA CIÊNCIA DAS PLANTAS DANINHAS - SBCPD. Procedimentos para instalação, avaliação e análise de experimentos com herbicidas. Londrina: 1995. $42 \mathrm{p}$.

TAYLOR-LOVELL, S. et al. Hydrolysis and soil adsorption of the labile herbicide isoxaflutole. Environ. Sci. Technol., v. 34, p. 3186-3190, 2000.

TAYLOR-LOVELL, S.; SIMS, G. K.; WAX, L. M. Effects of moisture, temperature, and biological activity on the degradation of isoxaflutole in soil. J. Agric. Food Chem., v. 50, p. 5626-5633, 2002.

VIDAL, R. A.; MEROTTO JR., A. Herbicidologia. Porto Alegre: Edição dos Autores, 2001. 75 p.

VIVIANI, F.; LITTLE, J. P.; PALLET, K. E. The mode of action of isoxaflutole. II. Characterization of the inhibition of carrot 4-hydroxyphenylpyruvate dioxygenase by the diketonitrile derivative of isoxaflutole. Pestic. Biochem. Physiol., v. 62, p. 125-134, 1998. 